\title{
Dasabuvir Inhibits Human Norovirus Infection in Human Intestinal Enteroids
}

\author{
(D) Tsuyoshi Hayashi, ${ }^{a}$ Kosuke Murakami, ${ }^{a}$ Junki Hirano, ${ }^{a}$ Yoshiki Fujii, ${ }^{a}$ Yoko Yamaoka, ${ }^{a}$ Hirofumi Ohashi, ${ }^{\text {a,b }}$ Koichi Watashi, ${ }^{a, b, c}$ \\ (D) Mary K. Estes, ${ }^{\text {d }}$ (D) Masamichi Muramatsua
}

\author{
aDepartment of Virology II, National Institute of Infectious Diseases, Tokyo, Japan \\ bDepartment of Applied Biological Science, Tokyo University of Science, Chiba, Japan \\ cResearch Center for Drug and Vaccine Development, National Institute of Infectious Diseases, Tokyo, Japan \\ dDepartments of Molecular Virology and Microbiology and of Medicine, Baylor College of Medicine, Houston, Texas, USA
}

ABSTRACT Human noroviruses (HuNoVs) are acute viral gastroenteritis pathogens that affect all age groups, yet no approved vaccines and drugs to treat HuNoV infection are available. In this study, we screened an antiviral compound library to identify compound(s) showing anti-HuNoV activity using a human intestinal enteroid (HIE) culture system in which HuNoVs are able to replicate reproducibly. Dasabuvir (DSB), which has been developed as an anti-hepatitis C virus agent, was found to inhibit HuNoV infection in HIEs at micromolar concentrations. Dasabuvir also inhibited severe acute respiratory syndrome coronavirus 2 (SARS-CoV-2) and human rotavirus A (RVA) infection in HIEs. To our knowledge, this is the first study to screen an antiviral compound library for HuNoV using HIEs, and we successfully identified dasabuvir as a novel anti-HuNoV inhibitor that warrants further investigation.

IMPORTANCE Although there is an urgent need to develop effective antiviral therapy directed against HuNoV infection, compound screening to identify anti-HuNoV drug candidates has not been reported so far. Using a human HIE culture system, our compound screening successfully identified dasabuvir as a novel anti-HuNoV inhibitor. Dasabuvir's inhibitory effect was also demonstrated in the cases of SARSCoV-2 and RVA infection, highlighting the usefulness of the HIE platform for screening antiviral agents against various viruses that target the intestines.

KEYWORDS acute gastroenteritis, antiviral drug, compound screen, dasabuvir, intestinal enteroids, norovirus

- uman noroviruses (HuNoVs) cause acute gastroenteritis and foodborne diseases among all age groups worldwide. HuNoVs often cause an economic burden to societies due to health care costs and loss of productivity and therefore pose a public health concern. Noroviruses are nonenveloped viruses possessing a positive-sense, single-stranded RNA genome whose length is approximately $7.5 \mathrm{~kb}$. They are genetically classified in 10 genogroups ( $\mathrm{Gl}$ to GX) and further divided into 48 genotypes based on their capsid and polymerase gene sequences (1). Among those, the Gll.4 genotype is the most frequently distributed and causes outbreaks in humans worldwide $(2,3)$.

Since a robust culture system to allow HuNoV replication was not established for almost 50 years, there are no established antiviral regimens or vaccines available. Recently, several HuNoV successive cultivation models employing a human B-cell line (4), tissue stem cell-derived human intestinal enteroids (HIEs) (5), human induced pluripotent stem cell-derived intestinal organoids (6), and zebrafish larvae (7) have been developed. The stem cell-derived HIE system is currently used by researchers worldwide to study HuNoV biology and viral inactivation strategies (8-14), although, to our
Citation Hayashi T, Murakami K, Hirano J, Fujii Y, Yamaoka Y, Ohashi H, Watashi K, Estes MK, Muramatsu M. 2021. Dasabuvir inhibits human norovirus infection in human intestinal enteroids. mSphere 6:e00623-21. https://doi .org/10.1128/mSphere.00623-21.

Editor Marcela F. Pasetti, University of Maryland School of Medicine

Copyright $\odot 2021$ Hayashi et al. This is an open-access article distributed under the terms of the Creative Commons Attribution 4.0 International license.

Address correspondence to Tsuyoshi Hayashi, hayashit@nih.go.jp, or Masamichi Muramatsu, muramatsu@nih.go.jp.

Received 9 July 2021

Accepted 12 October 2021

Published 3 November 2021 
knowledge, compound screens for identifying HuNoV antiviral agents have not been reported previously.

Drug repurposing is a time-saving, affordable strategy to discover new therapeutic uses for approved or developing drugs to treat other disease(s) apart from their original use(s) (15). This strategy is being widely utilized to establish effective therapeutics for the treatment of coronavirus disease 2019 (COVID-19). Indeed, numerous antiviral drugs, including remdesivir, ivermectin, or nelfinavir have been identified as promising candidates against severe acute respiratory syndrome coronavirus 2 (SARS-CoV-2) (15, 16). Here, with the HIE culture system, we screened an antiviral compound library composing 326 bioactive substances, including those targeting influenza virus, human immunodeficiency virus (HIV), or hepatitis C virus (HCV) to reassess their effect on HuNoV infection.

\section{RESULTS AND DISCUSSION}

Three-dimensional (3D) HIEs were dissociated and plated on collagen-coated 96-well plates to prepare two-dimensional (2D) monolayers (Fig. 1A). The cells were then differentiated by culturing them in differentiation medium, which does not include Wnt3A and R-spondin to support the stemness of HIEs. The differentiated HIE monolayers were inoculated with Gll.4 HuNoV in the presence of each compound dissolved in dimethyl sulfoxide (DMSO) for $1 \mathrm{~h}$ at $37^{\circ} \mathrm{C}$. DMSO was added to the wells without compound (DMSO control). For this screening step, one well was used to analyze each compound $(n=1)$. The cells were washed, then cultured in differentiation medium containing the compound for $24 \mathrm{~h}$. The infected cells and supernatant were then harvested, and viral replication was evaluated by reverse transcription-quantitative PCR (RT-qPCR) analysis to determine the HuNoV RNA genome equivalents (GEs) (Fig. 1B). Cytotoxicity for each compound was also determined by lactate dehydrogenase (LDH) assay. First, to evaluate the reproducibility of our HIE system with respect to HuNoV growth throughout the screening, we plotted the level of viral GEs at 1 or $24 \mathrm{~h}$ postinfection (hpi) from 7 independent experiments that were used for the compound screen. The fold changes of viral GEs between 1 and $24 \mathrm{hpi}$ in each experiment ranged from 65 to 230 (mean \pm standard deviation $[S D], 104.3 \pm 58.3$ ). A positive control, 2'-C-methylcytidine (2-CMC), completely blocked viral infection without any cytotoxicity in all experiments, consistent with the results of a previous report (Fig. 1C and D) (11). These results demonstrate that our HIE cultivation system reproducibly supports HuNoV replication and is suitable for evaluating the effect of the compounds against HuNoV.

We next determined the relative percentages of HuNoV GE and cytotoxicity at 24 hpi by normalizing the data of compound-treated cells to that of DMSO-treated cells. The screening results were plotted as HuNoV GE (\%) versus cytotoxicity (\%) (Fig. 1E). Among 326 compounds tested, dasabuvir (DSB) showed the strongest inhibitory effect on HuNoV infection without compromising cell viability (Fig. 1E and Table S1 in the supplemental material). We then repeated the experiment with 3 technical replicates and confirmed its inhibitory effect against HuNoV infection (Fig. S1). DSB has been developed as a direct-acting anti-HCV drugs that targets HCV NS5B RNA-dependent RNA polymerase (RdRp) (17). So far, there have been no reports regarding its antiviral effects against HuNoV.

Next, we performed additional experiments with DSB at various concentrations ranging from $3.125 \mu \mathrm{M}$ to $50 \mu \mathrm{M}$ to calculate the $50 \%$ effective concentration $\left(\mathrm{EC}_{50}\right)$ and $50 \%$ cytotoxic concentration $\left(\mathrm{CC}_{50}\right)$ values. DSB treatment alone showed no cytotoxicity, except for the highest concentration $(50 \mu \mathrm{M})$, which showed a $17 \%$ reduction of cellular ATP (cell viability) or a 10\% increase of LDH release (cytotoxicity), compared to those of the DMSO control (Fig. S2). Again, DSB did not induce cytotoxicity, except at the highest dose $(50 \mu \mathrm{M})$, in $J 2$ monolayers infected with Gll.4 HuNoV, whereas it showed a dose-dependent inhibition of viral replication with an $\mathrm{EC}_{50}$ value of $11.71 \mu \mathrm{M}$ (Fig. 2A). To ascertain the authenticity of DSB's inhibitory effect, we repeated the experiment with the identical compound from different sources and found that the results were comparable 
A

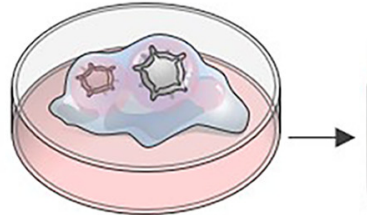

Three dimensional enteroids
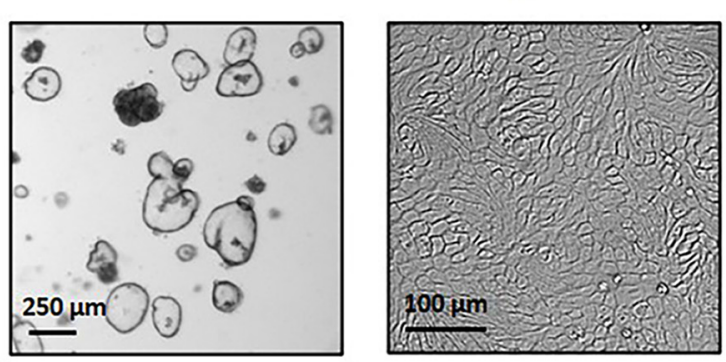

Monolayered enteroids

D

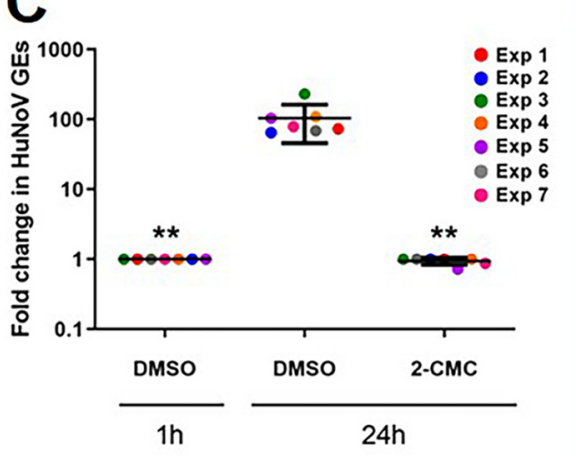

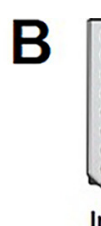
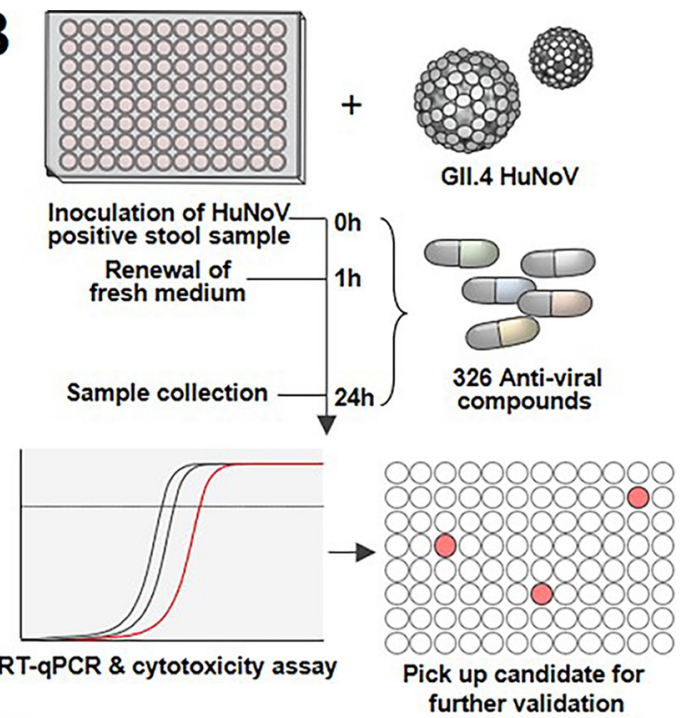

E

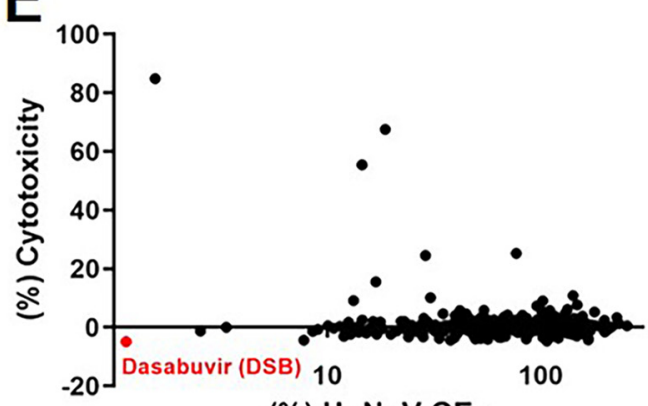

(\%) HuNoV GEs

FIG 1 Screening for antiviral compounds that inhibit human norovirus (HuNoV) infection in human intestinal enteroids (HIEs). (A and B) Schematic illustrations of compound screening. Three-dimensional HIEs (J2) were dissociated into single cells using TrypLE enzyme and plated in a 96-well plate to culture them as 2D monolayers. Differentiated HIE monolayers were then inoculated with Gll.4 HuNoV-containing stool filtrates in the presence of the compounds $(10 \mu \mathrm{M}, n=1)$. After $1 \mathrm{~h}$ incubation at $37^{\circ} \mathrm{C}$, the cells were washed and then cultured in differentiation medium containing the compounds $(10 \mu \mathrm{M})$ in a $100-\mu$ l volume until $24 \mathrm{~h}$ postinfection (hpi). Viral RNA extracted from the cells and $75 \mu \mathrm{l}$ of supernatant at 1 or $24 \mathrm{hpi}$ were subjected to reverse transcription-quantitative PCR (RT-qPCR) to measure viral genome equivalents (GEs). The rest of the supernatant was subjected to lactate dehydrogenase (LDH) assay to measure cytotoxicity. (C) HuNoV replication in $\mathrm{J} 2$ monolayers throughout the screening. We performed 7 experiments to screen all 326 compounds. Dimethyl sulfoxide (DMSO) and 2'-C-methylcytidine (2-CMC; $389 \mu \mathrm{M}$ ) were used as the controls in every test. Viral GEs in DMSO and 2-CMC-treated samples at $24 \mathrm{hpi}$ were normalized to the DMSO control at $1 \mathrm{hpi}$. ${ }^{*}, P<0.01$ versus DMSO control at $24 \mathrm{hpi}$, one-way analysis of variance (ANOVA) followed by Dunnett's multiple-comparison test. (D) Cytotoxicity of 2-CMC in J2 monolayers at $24 \mathrm{hpi}$. Results were normalized to the DMSO control. (E) Scatterplot of the \% HuNoV GEs versus \% cytotoxicity for all tested compounds. Results were normalized to the DMSO control. DSB, dasabuvir.

(Fig. S3). Dose-dependent reduction of viral replication by DSB was also observed in J2 HIE monolayers infected with a different HuNoV strain GII.3 (Fig. 2B). We further assessed DSB's inhibitory effect using J3 HIEs established from an independent donor following infection with Gll.3 or Gll.4 HuNoV and observed the same trends (Fig. 2C and D). Taken together, DSB exerted an inhibitory effect on two HuNoV genotypes and HIEs established from distinct individuals, suggesting that this effect is likely to be neither genotype nor HIE (donor) dependent.

Next, we tested the effect of DSB on infection with human rotavirus A (RVA) and SARS-CoV-2, both of which has been previously reported to be able to infect and replicate HIEs (18-20). Two concentrations of DSB were used in these studies, namely, noneffective $(6.25 \mu \mathrm{M})$ and effective concentration $(20 \mu \mathrm{M})$ against HuNoV. As shown in Fig. $3 \mathrm{~A}$ and $\mathrm{B}, \mathrm{DSB}$ showed a moderate antiviral effect (2.75-fold decrease) on RVA infection at a concentration of $20 \mu \mathrm{M}$, while it almost completely inhibited (26.9-fold decrease) SARS-CoV-2 infection in J2 HIE monolayers. We also confirmed DSB's inhibition with no 


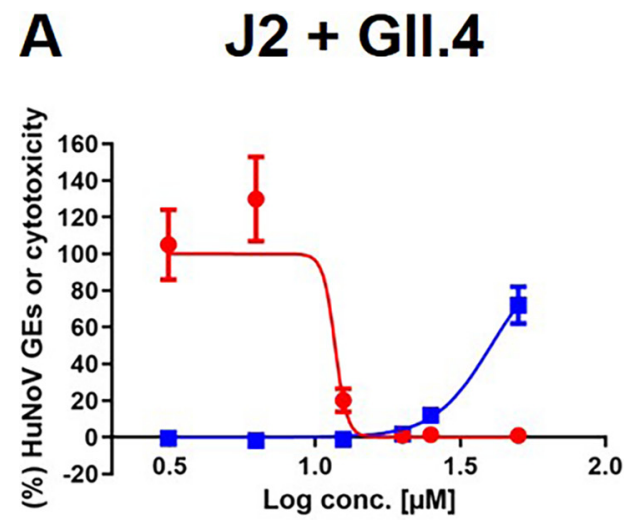

B $\quad \mathrm{J} 2+\mathrm{GII.3}$

(\%) HuNoV GEs $\left(E_{50}=11.71 \mu \mathrm{M}\right)$

(\%) Cytotoxicity $\left(\mathrm{CC}_{50}=\mathbf{4 0 . 3 2} \mu \mathrm{M}\right)$

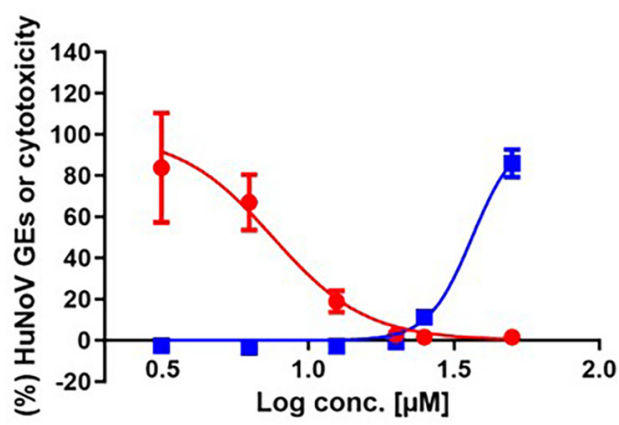

(\%) HuNoV GEs $\left(E_{50}=7.55 \mu \mathrm{M}\right)$

(\%) Cytotoxicity $\left(\mathrm{CC}_{50}=36.45 \mu \mathrm{M}\right)$
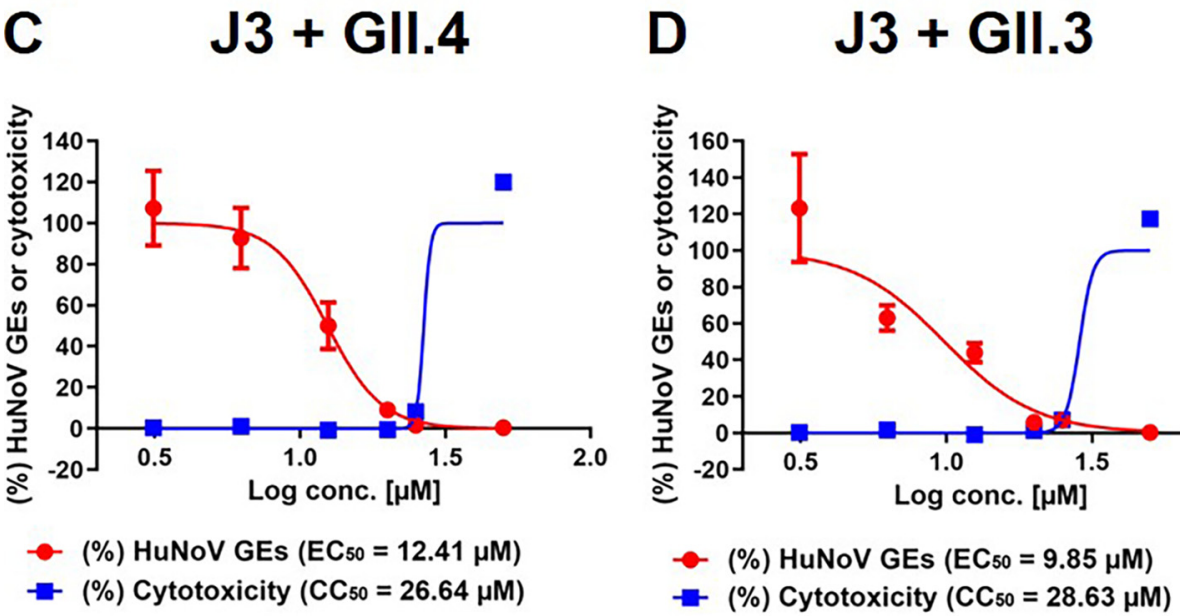

(\%) HuNoV GEs $\left(E_{50}=12.41 \mu \mathrm{M}\right)$

(\%) Cytotoxicity $\left(\mathrm{CC}_{50}=26.64 \mu \mathrm{M}\right)$

(\%) Cytotoxicity $\left(\mathrm{CC}_{50}=\mathbf{2 8 . 6 3 \mu \mathrm { M } )}\right.$

FIG 2 Effect of dasabuvir on HuNoV infection in HIE monolayers. J2 (A and B) or J3 (C and D) HIE monolayers were inoculated with GIl.4 (A and C) or GIl.3 (B and D) HuNoV-containing stool filtrate in the presence of DSB at the indicated concentrations and were cultured until $20 \mathrm{hpi}$. The percentages of HuNoV GEs (red lines) and cytotoxicity (blue lines) were determined as in Fig. 1 and were normalized to the DMSO control. Values represent the mean \pm standard deviation $(\mathrm{SD})(n \geq 6)$. $\mathrm{EC}_{50}, 50 \%$ effective concentration; $\mathrm{CC}_{50}, 50 \%$ cytotoxic concentration.

cytotoxicity using VeroE6/TMPRSS2 cells, which are highly susceptible to SARS-CoV-2 infection (Fig. 3C and D, and Fig. S4) (21).

The mechanism of action for the virus inhibitions by DSB remains to be elucidated. DSB is a nonnucleotide inhibitor of HCV NS5B RdRp that likely binds to the palm domain of NS5B and thereby prevents elongation of the nascent viral genome (22). Therefore, it might also target the RdRp of other viruses, such as HuNoV and SARSCoV-2, possibly because of the presence of conserved sequences being targeted by DSB. Indeed, there is a report showing that DSB partially inhibits the RdRp activity of Middle East respiratory syndrome coronavirus (MERS-CoV) (23). Targeting of viral protease might be another scenario for the inhibition; a very recent virtual screening study predicted that dasabuvir has the potential to inhibit 3-chymotrypsin-like protease (3CLPRO) of SARS-CoV-2 (24).

With an HCV subgenomic replicon system, DSB inhibits HCV of genotype 1 with $\mathrm{EC}_{50}$ values of $<10 \mathrm{nM}$ (22). In contrast, DSB inhibits HuNoV infection with $\mathrm{EC}_{50}$ values ranging between 7.55 and $12.41 \mu \mathrm{M}$ (Fig. 2), which is comparable to its effectiveness in inhibiting RdRp activity of MERS-CoV-2 (23) or infection by vector-borne flaviviruses (25). This implies that a higher concentration is required to exert an antiviral effect on non-HCV viruses, possibly due to lower binding efficiency of DSB to non-HCV RdRp(s) or to unknown mechanism(s) of its inhibitory action. A pharmacokinetic study of DSB 


\section{A}
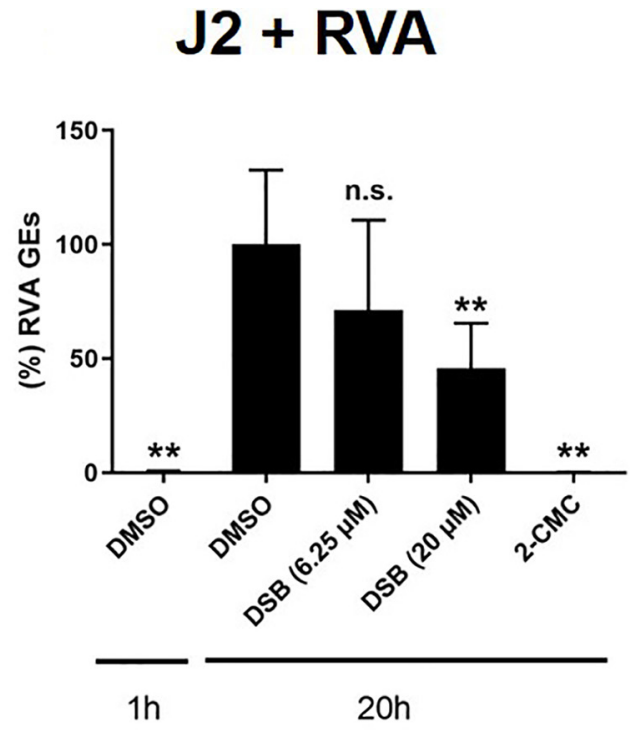

C

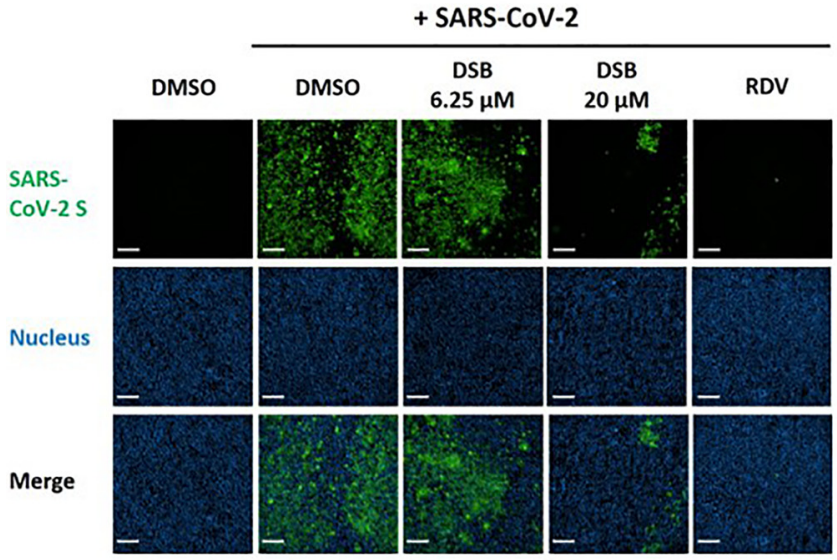

\section{B J2 + SARS-CoV-2}

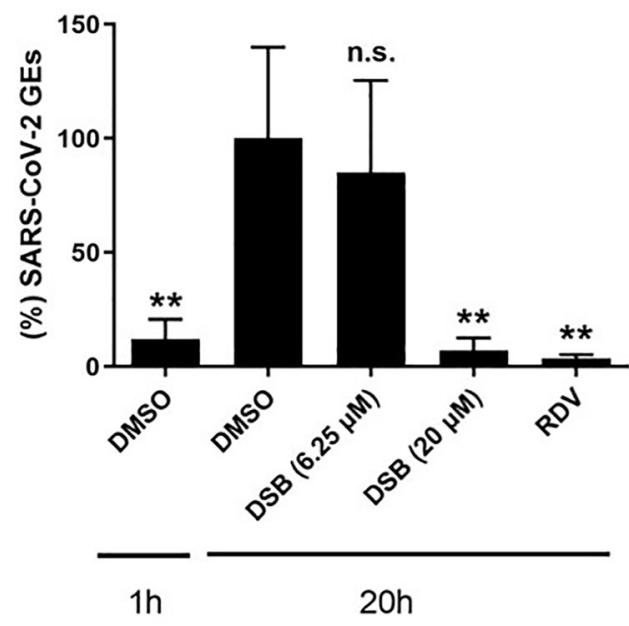

D

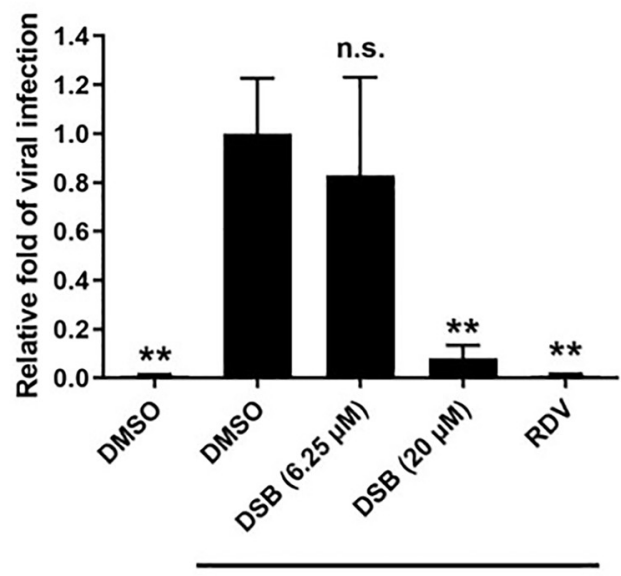

+ SARS-CoV-2

FIG 3 Dasabuvir inhibits SARS-CoV-2 infection in J2 HIE monolayers and VeroE6/TMPRSS2 cells. (A and B) J2 HIE monolayers were inoculated with RVA (A) and SARS-CoV-2 (B) in the presence of the indicated compounds and were cultured until 20 hpi. 2-CMC (389 $\mu \mathrm{M}$ ) or remdesivir (RDV; $10 \mu \mathrm{M}$ ) were used as positive controls. The percentages of viral GEs were determined by RT-qPCR, and were normalized to the DMSO control at $20 \mathrm{hpi}$. Values represent the mean \pm SD $(n \geq 5)$. (C and D) VeroE6/TMPRSS2 cells were left uninfected or were infected with SARS-CoV-2 for $20 \mathrm{~h}$ in the presence of the indicated compounds. The cells were then stained with anti-SARS-CoV-2 spike (S) RBD monoclonal antibody and 4',6-diamidino-2-phenylindole (DAPI), followed by imaging analysis. (C) Representative fluorescence images showing SARS-CoV-2 S protein (green) and cell nucleus (blue). Bar, $200 \mu \mathrm{m}$. (D) The percentages of infected cells were normalized to those of DMSO-treated cells infected with SARS-CoV- 2 at 20 hpi. Values represent the mean \pm SD $(n \geq 8)$. ${ }^{* *}, P<0.01$ versus DMSO control at 20 hpi, one-way ANOVA followed by Dunnett's multiple-comparison test. n.s., not significant $(P>0.05)$.

in healthy volunteers demonstrated that the maximum plasma concentration $\left(C_{\max }\right)$ is reached at approximately $5.61 \mu \mathrm{M}$ after administration of DSB (1,000 mg twice a day [BID]) for 10 days (26), which is slightly less than the $\mathrm{EC}_{50}$ values (7.55 to $12.41 \mu \mathrm{M}$ ) determined in HIEs. Further in vivo studies are needed to determine the optimal treatment regimen of DSB that elicits anti-HuNoV activity with no toxicity in a clinical setting.

In summary, through the screening of an antiviral compound library, we identified DSB as a novel HuNoV inhibitor that warrants further clinical investigation. To our knowledge, this was the first time bona fide anti-HuNoV agents have been identified using the HIE culture system. Our study also sheds light on the usefulness of the HIE platform for investigation of anti-HuNoV agents and/or host factors regulating HuNoV 
infection, which will contribute to better understanding of the HuNoV life cycle and to the development of vaccine and antiviral regimens.

\section{MATERIALS AND METHODS}

Cells. Human intestinal enteroid (HIE) J2 and J3 lines, established from jejunal biopsy specimens of secretor-positive adults (5), were provided from Baylor College of Medicine under a material transfer agreement. The study protocol was approved by the Review Board of the National Institute of Infectious Diseases in Japan. Wnt3a-producing cells were kindly provided by the Baylor College of Medicine. Rspondin- and Noggin-producing cells were kindly provided by Calvin Kuo (Palo Alto, CA) and Gijs van den Brink (University of Amsterdam, Netherlands), respectively. HIEs were grown as multilobular, 3dimensional (3D) cultures in Matrigel and were maintained in complete medium with growth factors [CMGF(+)] or IntestiCult organoid growth medium (human) (Veritas) as previously described $(5,10,19)$. Monkey kidney cell line MA104 was maintained in Dulbecco's modified Eagle's medium (DMEM) supplemented with $10 \%$ fetal bovine serum (FBS), $100 \mathrm{U} / \mathrm{ml}$ penicillin, and $100 \mu \mathrm{g} / \mathrm{ml}$ streptomycin. VeroE6/ TMPRSS2 (JCRB1819, VeroE6 cell overexpressing the transmembrane protease, serine 2 [TMPRSS2]) (21) was purchased from JCRB Cell Bank (Osaka, Japan) and was maintained in DMEM supplemented with $10 \%$ FBS, $100 \mathrm{U} / \mathrm{ml}$ penicillin, $100 \mu \mathrm{g} / \mathrm{ml}$ streptomycin, and $1 \mathrm{mg} / \mathrm{ml} \mathrm{G} 418$ (Nacalai).

Viruses. Ten percent stool suspensions containing human norovirus (HuNoV) were prepared as described previously (5) and kept at $-80^{\circ} \mathrm{C}$ before use. Human rotavirus A (RVA) Wa strain was propagated in MA104 cells in the presence of trypsin. Severe acute respiratory syndrome coronavirus 2 (SARSCoV-2), 2019-nCoV/Japan/TY/WK-521/2020 strain (WK-521), was isolated previously (21) and propagated in VeroE6/TMPRSS2 cells. Virus titer of the SARS-CoV-2 was determined by $50 \%$ tissue culture infectious dose $\left(\mathrm{TCID}_{50}\right)$ assay in VeroE6/TMPRSS2 cells (21).

Compounds. An antivirus compound library (326 compounds, $10 \mathrm{mM}$ solution in DMSO, L1700) was purchased from TargetMol. To validate antiviral effect, 3 individual dasabuvir (DSB) stocks were purchased from different companies (catalog no. T3489, TargetMol; catalog no. S5402, Selleck; and catalog no. 18482, Cayman Chemical). 2'-C-methylcytidine (2-CMC; catalog no. 22887) was purchased from Cayman Chemical. Remdesivir (RDV; catalog no. S8932) was purchased from Selleck.

Infection of HIEs with viruses. Virus infection in differentiated two-dimensional (2D) HIE monolayers was performed following a previously described protocol with minor modification $(5,10,19)$. Briefly, 3D J2 (passages 19 to 35) or J3 (passages 25 to 27) HIE lines were dissociated with TrypLE Express (Thermo Fisher) into single cells, after which they were seeded onto collagen IV-coated 96well plates at the number of approximately $\sim 10^{5}$ cells/well in CMGF(+) or IntestiCult medium supplemented with ROCK inhibitor Y-27632 (10 $\mu \mathrm{M}$; Sigma) for 2 days. After 2 days, the cells typically reach $\sim 100 \%$ confluence. The medium was then removed, and the cells were maintained in the differentiation medium for another 2 days.

For HuNoV infection, the J2 and J3 HIE monolayers were inoculated with $10 \%$ stool filtrate containing $4.3 \times 10^{5}$ genome equivalents (GEs) of GII.3 [GII.P21] (TCH04-577) $(5,12)$ or Gll.4 [GII.P16] HuNoV in the presence of $500 \mu \mathrm{M}$ glycochenodeoxycholic acid (GCDCA), which is required for Gll.3 HuNoV infection and promotes GIl.4 infection $(5,12)$. For RVA infection, the J2 HIE monolayers were inoculated with the Wa strain at $2.48 \times 10^{8} \mathrm{GEs} /$ well that were pretreated with $10 \mu \mathrm{g} / \mathrm{ml}$ trypsin (Sigma) for $1 \mathrm{~h}$ at $37^{\circ} \mathrm{C}$ to activate the VP4 spike protein (27). For SARS-CoV-2 infection, the J2 monolayers were incubated with WK-521 at $8.1 \times 10^{8} \mathrm{GEs} /$ well. After $1 \mathrm{~h}$ of incubation at $37^{\circ} \mathrm{C}$, the cells were washed twice with complete medium without growth factors $[\mathrm{CMGF}(-)]$ to remove unbound viruses. The cells were then incubated with differentiation medium in the presence (HuNoV) or absence (RVA and SARS-CoV-2) of GCDCA until 20 to $24 \mathrm{~h}$ postinfection (hpi). The indicated compounds or DMSO were added to the medium throughout the infection process. The final concentration of DMSO was $0.5 \%$. The cells and medium were then harvested and subjected to RNA extraction.

RNA extraction and RT-qPCR. Total RNA was extracted from the infected cells and/or media using the Direct-zol RNA MiniPrep kit (Zymo Research) according to the manufacturer's instruction. RT-qPCR analysis to determine viral RNA GEs of HuNoV, RVA, and SARS-CoV-2 was performed using TaqMan Fast virus one-step master mix (Thermo Fisher) and specific primer/probe sets as described previously $(5,28,29)$.

Cell viability assay. Cytotoxicity or cell viability upon compound treatment was determined using the Cytotoxicity LDH assay kit-WST (Dojindo) or the CellTiter-Glo luminescent cell viability assay (Promega), respectively, according to the respective manufacturer's instructions.

Immunofluorescence assay. Confluent VeroE6/TMPRSS2 cells cultured in 96-well plate (CellCarrier-96 Ultra; Perkin Elmer) were infected with SARS-CoV-2 at a multiplicity of infection (MOI) of 0.003 for $20 \mathrm{~h}$ at $37^{\circ} \mathrm{C}$. The infected cells were then fixed with $4 \%$ paraformaldehyde in Dulbecco's phosphate-buffered saline (D-PBS) for $30 \mathrm{~min}$ and permeabilized with $0.2 \%$ Triton X-100 in D-PBS for $15 \mathrm{~min}$. The cells were stained for SARS-CoV-2 spike (S) protein using rabbit anti-SARS-CoV-2 spike receptor-binding domain monoclonal antibody (1:3,000, clone HL1003, catalog no. GTX635792; GeneTex) followed by goat anti-rabbit IgG Alexa Fluor 488 (1:1,000; Life Technologies). Cell nuclei were stained with $1 \mu \mathrm{g} / \mathrm{ml} 4^{\prime}, 6$-diamidino2-phenylindole (DAPI) solution (Dojindo). The cells were then imaged using the Operetta CLS HighContent Analysis System (Perkin Elmer) and the percentage of SARS-CoV-2-positive cells (infectivity) in each well were calculated by counting SARS-CoV-2 S- and DAPI-positive cells using Harmony software (Perkin Elmer).

Data analysis and statistics. All experiments except for compound screening (Fig. 1 and Fig. S1 in the supplemental material), were performed at least two times with more than two technical replicates, and results are shown as mean \pm SD $(n \geq 4)$. Statistical analysis was performed with analysis of variance 
(ANOVA) followed by Dunnett's multiple-comparison test or two-tailed Student's $t$ test using GraphPad Prism 9 software. $P$ values of $<0.05$ was considered statistically significant. A dose response curve was created by a nonlinear regression model, and the $50 \%$ effective concentration $\left(\mathrm{EC}_{50}\right)$ and the cytotoxic concentration $\left(\mathrm{CC}_{50}\right)$ were calculated using GraphPad Prism 9 software.

\section{SUPPLEMENTAL MATERIAL}

Supplemental material is available online only.

FIG S1, TIF file, 1.5 MB.

FIG S2, TIF file, 0.8 MB.

FIG S3, TIF file, 1.3 MB.

FIG S4, TIF file, $0.9 \mathrm{MB}$.

TABLE S1, XLSX file, $0.02 \mathrm{MB}$.

\section{ACKNOWLEDGMENTS}

This study was supported by the Japan Society for the Promotion of Science (KAKENHI grant JP20K07520 to T.H.), by the Japan Agency for Medical Research and Development (AMED) (grants JP21fk0108149 to K.M. and T.H., JP21fk0108102 to M.M. and K.M., JP21fk0108121 to K.M., JP21wm0225009 to M.M., and JP21fk0108121 to Y.F.), and by NIH grants P30 DK056338 and PO1 AI057788 (to M.K.E.).

We thank Hiroyuki Shimizu, Shutoku Matsuyama, and Noriyo Nagata (National Institute of Infectious Diseases) for technical assistance.

M.K.E. is named as an inventor on patents related to cloning and cultivation of the Norwalk virus genome and is a consultant to and received research funding from Takeda Vaccines, Inc.

\section{REFERENCES}

1. Chhabra P, de Graaf M, Parra Gl, Chan MC, Green K, Martella V, Wang Q, White PA, Katayama K, Vennema H, Koopmans MPG, Vinjé J. 2019. Updated classification of norovirus genogroups and genotypes. J Gen Virol 100:1393-1406. https://doi.org/10.1099/jgv.0.001318.

2. Cannon JL, Bonifacio J, Bucardo F, Buesa J, Bruggink L, Chan MC, Fumian TM, Giri S, Gonzalez MD, Hewitt J, Lin JH, Mans J, Muñoz C, Pan CY, Pang XL, Pietsch C, Rahman M, Sakon N, Selvarangan R, Browne H, Barclay L, Vinjé J. 2021. Global trends in norovirus genotype distribution among children with acute gastroenteritis. Emerg Infect Dis 27:1438-1445. https://doi.org/10 .3201/eid2705.204756.

3. Mallory ML, Lindesmith LC, Graham RL, Baric RS. 2019. Gll.4 human norovirus: surveying the antigenic landscape. Viruses 11:177. https://doi.org/ 10.3390/v11020177.

4. Jones MK, Watanabe M, Zhu S, Graves CL, Keyes LR, Grau KR, GonzalezHernandez MB, lovine NM, Wobus CE, Vinjé J, Tibbetts SA, Wallet SM, Karst SM. 2014. Enteric bacteria promote human and mouse norovirus infection of B cells. Science 346:755-759. https://doi.org/10.1126/science.1257147.

5. Ettayebi K, Crawford SE, Murakami K, Broughman JR, Karandikar U, Tenge VR, Neill FH, Blutt SE, Zeng XL, Qu L, Kou B, Opekun AR, Burrin D, Graham DY, Ramani S, Atmar RL, Estes MK. 2016. Replication of human noroviruses in stem cell-derived human enteroids. Science 353:1387-1393. https://doi .org/10.1126/science.aaf5211.

6. Sato S, Hisaie K, Kurokawa S, Suzuki A, Sakon N, Uchida Y, Yuki Y, Kiyono H. 2019. Human norovirus propagation in human induced pluripotent stem cell-derived intestinal epithelial cells. Cell Mol Gastroenterol Hepatol 7:686-688.e5. https://doi.org/10.1016/j.jcmgh.2018.11.001.

7. Van Dycke J, Ny A, Conceição-Neto N, Maes J, Hosmillo M, Cuvry A, Goodfellow I, Nogueira TC, Verbeken E, Matthijnssens J, de Witte P, Neyts J, Rocha-Pereira J. 2019. A robust human norovirus replication model in zebrafish larvae. PLoS Pathog 15:e1008009. https://doi.org/10 .1371/journal.ppat.1008009.

8. Lin SC, Qu L, Ettayebi K, Crawford SE, Blutt SE, Robertson MJ, Zeng XL, Tenge VR, Ayyar BV, Karandikar UC, Yu X, Coarfa C, Atmar RL, Ramani S, Estes MK. 2020. Human norovirus exhibits strain-specific sensitivity to host interferon pathways in human intestinal enteroids. Proc Natl Acad Sci U S A 117:23782-23793. https://doi.org/10.1073/pnas.2010834117.

9. Alvarado G, Ettayebi K, Atmar RL, Bombardi RG, Kose N, Estes MK, Crowe JE, Jr. 2018. Human monoclonal antibodies that neutralize pandemic Gll.4 noroviruses. Gastroenterology 155:1898-1907. https://doi.org/10.1053/j .gastro.2018.08.039.

10. Ettayebi K, Tenge VR, Cortes-Penfield NW, Crawford SE, Neill FH, Zeng XL, Yu X, Ayyar BV, Burrin D, Ramani S, Atmar RL, Estes MK. 2021. New insights and enhanced human norovirus cultivation in human intestinal enteroids. mSphere 6:e01136-20. https://doi.org/10.1128/mSphere.01136-20.

11. Hosmillo M, Chaudhry Y, Nayak K, Sorgeloos F, Koo BK, Merenda A, Lillesto R, Drumright L, Zilbauer M, Goodfellow I. 2020. Norovirus replication in human intestinal epithelial cells is restricted by the interferon-induced JAK/ STAT signaling pathway and RNA polymerase II-mediated transcriptional responses. mBio 11:e00215-20. https://doi.org/10.1128/mBio.00215-20.

12. Murakami K, Tenge VR, Karandikar UC, Lin SC, Ramani S, Ettayebi K, Crawford SE, Zeng XL, Neill FH, Ayyar BV, Katayama K, Graham DY, Bieberich E, Atmar RL, Estes MK. 2020. Bile acids and ceramide overcome the entry restriction for Gll.3 human norovirus replication in human intestinal enteroids. Proc Natl Acad Sci U S A 117:1700-1710. https://doi.org/ 10.1073/pnas.1910138117.

13. Costantini V, Morantz EK, Browne H, Ettayebi K, Zeng XL, Atmar RL, Estes MK, Vinjé J. 2018. Human norovirus replication in human intestinal enteroids as model to evaluate virus inactivation. Emerg Infect Dis 24:1453-1464. https://doi.org/10.3201/eid2408.180126.

14. Chan JCM, Mohammad KN, Zhang L-Y, Wong SH, Chan MC-W. 2021. Targeted profiling of immunological genes during norovirus replication in human intestinal enteroids. Viruses 13:155. https://doi.org/10 .3390/v13020155.

15. Low ZY, Farouk IA, Lal SK. 2020. Drug repositioning: new approaches and future prospects for life-debilitating diseases and the COVID-19 pandemic outbreak. Viruses 12:1058. https://doi.org/10.3390/v12091058.

16. Watashi K. 2021. Identifying and repurposing antiviral drugs against severe acute respiratory syndrome coronavirus 2 with in silico and in vitro approaches. Biochem Biophys Res Commun 538:137-144. https://doi .org/10.1016/j.bbrc.2020.10.094.

17. Trivella JP, Gutierrez J, Martin P. 2015. Dasabuvir: a new direct antiviral agent for the treatment of hepatitis C. Expert Opin Pharmacother 16: 617-624. https://doi.org/10.1517/14656566.2015.1012493.

18. Saxena K, Blutt SE, Ettayebi K, Zeng XL, Broughman JR, Crawford SE, Karandikar UC, Sastri NP, Conner ME, Opekun AR, Graham DY, Qureshi W, Sherman V, Foulke-Abel J, In J, Kovbasnjuk O, Zachos NC, Donowitz M, Estes MK. 2016. Human intestinal enteroids: a new model to study human 
rotavirus infection, host restriction, and pathophysiology. J Virol 90:43-56. https://doi.org/10.1128/JVI.01930-15.

19. Zou WY, Blutt SE, Crawford SE, Ettayebi K, Zeng XL, Saxena K, Ramani S, Karandikar UC, Zachos NC, Estes MK. 2019. Human intestinal enteroids: new models to study gastrointestinal virus infections. Methods Mol Biol 1576:229-247. https://doi.org/10.1007/7651_2017_1.

20. Lamers MM, Beumer J, van der Vaart J, Knoops K, Puschhof J, Breugem TI, Ravelli RBG, Paul van Schayck J, Mykytyn AZ, Duimel HQ, van Donselaar E, Riesebosch S, Kuijpers HJH, Schipper D, van de Wetering WJ, de Graaf M, Koopmans M, Cuppen E, Peters PJ, Haagmans BL, Clevers H. 2020. SARSCoV-2 productively infects human gut enterocytes. Science 369:50-54. https://doi.org/10.1126/science.abc1669.

21. Matsuyama S, Nao N, Shirato K, Kawase M, Saito S, Takayama I, Nagata N, Sekizuka T, Katoh H, Kato F, Sakata M, Tahara M, Kutsuna S, Ohmagari N, Kuroda M, Suzuki T, Kageyama T, Takeda M. 2020. Enhanced isolation of SARS-CoV-2 by TMPRSS2-expressing cells. Proc Natl Acad Sci U S A 117: 7001-7003. https://doi.org/10.1073/pnas.2002589117.

22. Kati W, Koev G, Irvin M, Beyer J, Liu Y, Krishnan P, Reisch T, Mondal R, Wagner R, Molla A, Maring C, Collins C. 2015. In vitro activity and resistance profile of dasabuvir, a nonnucleoside hepatitis $C$ virus polymerase inhibitor. Antimicrob Agents Chemother 59:1505-1511. https://doi.org/10.1128/AAC.04619-14.

23. Min JS, Kim GW, Kwon S, Jin YH. 2020. A cell-based reporter assay for screening inhibitors of MERS coronavirus RNA-dependent RNA polymerase activity. J Clin Med 9:2399. https://doi.org/10.3390/jcm9082399.
24. Jade $D$, Ayyamperumal $S$, Tallapaneni $V$, Joghee Nanjan $C M$, Barge $S$, Mohan S, Nanjan MJ. 2021. Virtual high throughput screening: potential inhibitors for SARS-CoV-2 PL ${ }^{\mathrm{PRO}}$ and $3 \mathrm{CL}^{\mathrm{PRO}}$ proteases. Eur J Pharmacol 901:174082. https://doi.org/10.1016/j.ejphar.2021.174082.

25. Stefanik M, Valdes JJ, Ezebuo FC, Haviernik J, Uzochukwu IC, Fojtikova M, Salat J, Eyer L, Ruzek D. 2020. FDA-approved drugs efavirenz, tipranavir, and dasabuvir inhibit replication of multiple flaviviruses in Vero cells. Microorganisms 8:599. https://doi.org/10.3390/microorganisms8040599.

26. King JR, Zha J, Khatri A, Dutta S, Menon RM. 2017. Clinical pharmacokinetics of dasabuvir. Clin Pharmacokinet 56:1115-1124. https://doi.org/10 .1007/s40262-017-0519-3.

27. Crawford SE, Mukherjee SK, Estes MK, Lawton JA, Shaw AL, Ramig RF, Prasad BV. 2001. Trypsin cleavage stabilizes the rotavirus VP4 spike. J Virol 75:6052-6061. https://doi.org/10.1128/JVI.75.13.6052-6061.2001.

28. Freeman MM, Kerin T, Hull J, McCaustland K, Gentsch J. 2008. Enhancement of detection and quantification of rotavirus in stool using a modified real-time RT-PCR assay. J Med Virol 80:1489-1496. https://doi.org/10 $.1002 / j m v .21228$.

29. Matsuyama S, Kawase M, Nao N, Shirato K, Ujike M, Kamitani W, Shimojima M, Fukushi S. 2020. The inhaled steroid ciclesonide blocks SARS-CoV-2 RNA replication by targeting the viral replication-transcription complex in cultured cells. J Virol 95:e01648-20. https://doi.org/10 $.1128 / \mathrm{JVI} .01648-20$. 